Review Article

\title{
Helicobacter pylori Infection, Chronic Inflammation, and Genomic Transformations in Gastric MALT Lymphoma
}

\author{
Magdalena Witkowska and Piotr Smolewski \\ Department of Experimental Hematology, Medical University of Lodz, Ciolkowskiego 2, 93-510 Lodz, Poland \\ Correspondence should be addressed to Piotr Smolewski; piotr_smolewski@wp.pl
}

Received 4 January 2013; Accepted 11 February 2013

Academic Editor: David Bernardo Ordiz

Copyright ( 2013 M. Witkowska and P. Smolewski. This is an open access article distributed under the Creative Commons Attribution License, which permits unrestricted use, distribution, and reproduction in any medium, provided the original work is properly cited.

\begin{abstract}
Nowadays, it is believed that the main role in the development of gastric mucosa-associated lymphoid tissue (MALT) lymphoma plays Helicobacter pylori infection. This world-wide distributed bacteria is in charge of most cases of not only upper gastrointestinal tract disorders but also some of extragastric problems. Constant stimulation of the immune system causes a B-lymphocytes proliferation, which is considered to be responsible for the neoplastic transformation. On the other hand, there are $10 \%-20 \%$ of patients who do not respond to Helicobacter pylori eradication treatment. This group has often a chromosome translocation, which suggests that there is another unknown, so far, pathogenetic mechanism of MALT lymphoma. Majority of genetic abnormalities are connected with nuclear factor- $\kappa \mathrm{B}(\mathrm{NF}-\kappa \mathrm{B})$ pathway, which activates the uncontrolled proliferation of neoplastic cells. Translocations already described in studies are $\mathrm{t}(11 ; 18)(\mathrm{q} 21 ; \mathrm{q} 21)$, which is the most common, $\mathrm{t}(14 ; 18)(\mathrm{q} 32 ; \mathrm{q} 21), \mathrm{t}(14 ; 18)(\mathrm{q} 32 ; \mathrm{q} 21)$, and $\mathrm{t}(3 ; 14)$ (p14.1; 32 ). This non-Hodgkin's lymphoma is an indolent type originated outside lymph nodes. In more than $50 \%$ of cases, it occurs in the stomach. Occasionally, it can be found in salivary and thyroid gland, lung, breast, bladder, skin, or any other place in the human body. This paper is a review of the current knowledge on etiology, pathogenesis, treatment, and follow-up of gastric MALT lymphoma.
\end{abstract}

\section{Introduction}

The name of mucosa-associated lymphoid tissue (MALT) lymphoma was first established in 1983 by Isaacson and $\mathrm{Du}$ [1]. From the beginning, it was adopted well and is still used in an unchanged form. Marginal zone lymphoma of MALT is, apart from diffuse large B-cell lymphoma, the most frequent type of lymphoma that occurs in the stomach. What is important is that it can develop in almost every organ and tissue, for instance lungs, breast, thyroid gland, bladder, skin, or orbital adnexa. It is an indolent type, but clinical outcomes and response to treatment vary among patients. MALT lymphoma arises from the extranodal sites reach in B-lymphocytes, which appears in response to chronic antigenic stimulation caused by infection (Helicobacter pylori) or autoimmune process (Hashimoto disease). This disorder is the best example of how infectious pathogens and genetic abnormalities lead to malignant transformation. Gastric MALT lymphoma pathogenesis is a complex process including many gene alternations that result in cancer appearance. Better understanding of the background of the disease is crucial for discovering new prognostic factors, helpful in deciding when more aggressive treatment should be employed.

\section{Epidemiology}

The incidence of malignant lymphomas is at the rate of 3\%$4 \%$ of all malignancy worldwide and has been increasing during the last 50 years. Lately, some stabilization in the number of diagnosis was observed, but only in developed countries. Malignant lymphomas are observed to be more frequent in North America, Australia, and Europe than in Asia and Africa. MALT lymphomas determine almost $7 \%$ of all non-Hodgkin's lymphoma, and at least $40 \%$ is primarily located in stomach. It is confirmed that gastric MALT lymphoma occurs in younger patients than the rest 
of malignant lymphomas. The MALT lymphoma is mainly a disease of older adults, with a median age of 60 years. There is a gentle predominance of females [2]. In Asia, there is much higher proportions of MALT lymphomas, which can be caused by more frequent prevalence of Helicobacter pylori in this region of the world.

\section{Pathogenesis}

3.1. Infectious Background. Gastric MALT lymphoma pathogenesis is strictly connected with Helicobacter pylori infection. Although $90 \%$ of population worldwide have confirmed bacteria colonization, only $2 \%$ will develop malignant lymphoma. It was confirmed by Weber et al. [3] that almost $90 \%$ of patients with gastric MALT lymphoma are infected with Helicobacter pylori. This curved bacillus, previously called Campylobacter pyloridis, is a Gram negative pathogen found in the stomach. It was discovered by Marshall and Warren in 1980s [4]. From the beginning, Helicobacter pylori was classified as a higher class I carcinogen. Although over $80 \%$ of people are asymptomatic, chronic infection can lead to gastritis, gastric and duodenal ulcer, gastric adenocarcinoma, and MALT lymphoma $[5,6]$. Nowadays, it is widely accepted that Helicobacter pylori gastritis is crucial in an evolution of MALT lymphoma localized in stomach. It was confirmed by several studies that chronic gastric inflammation causes constant antigenic stimulation, which leads to clonal expansion of B-cell lymphocytes [7, 8].

In the gastric mucosal cells, there are elevated levels of some cytokines, including proliferation-inducing ligand (APRIL), which belongs to the tumour necrosis factor (TNF) family. The protein has a crucial role in $\mathrm{B}$-cell maturation and survival. APRIL is produced by macrophages present in the gastric MALT infiltrate, located close to the neoplastic cells [9]. APRIL may also induce B-cells transformation and the progression to the diffuse large B-cell lymphoma (Figure 1). The survival and transformation of $\mathrm{B}$ cells in malignant lymphoma require additional signals. They come either from $\mathrm{T}$ cells or directly by the antigenic autostimulation of lymphoma cells [1]. Gastric inflammation causes the appearance of a large number of macrophages, which, under a Helicobacter pylori infection, release large amounts of APRIL. This mechanism may be enhanced and maintained by the activated T lymphocytes. Importantly, a number of APRILproducing macrophages significantly decrease in complete remission after eradication therapy [9]. Thus, a new APRIL production-targeted therapy can be developed.

Other pathogens, are also suspected to play an important role in MALT lymphoma pathogenesis. There are bacteria such as Campylobacter jejuni, Borrelia burgdorferi, and Chlamydia psittaci and viruses like Hepatitis $C$ virus (HCV) that are potentially responsible for oncogenesis. These pathogens were found in histological material, but so far no strong evidences were established [10].

3.2. Autoimmune Disease. Patients with autoimmune disease have for sure higher risk of developing MALT lymphoma. Autoreactive B cells infiltrate the healthy organs and create

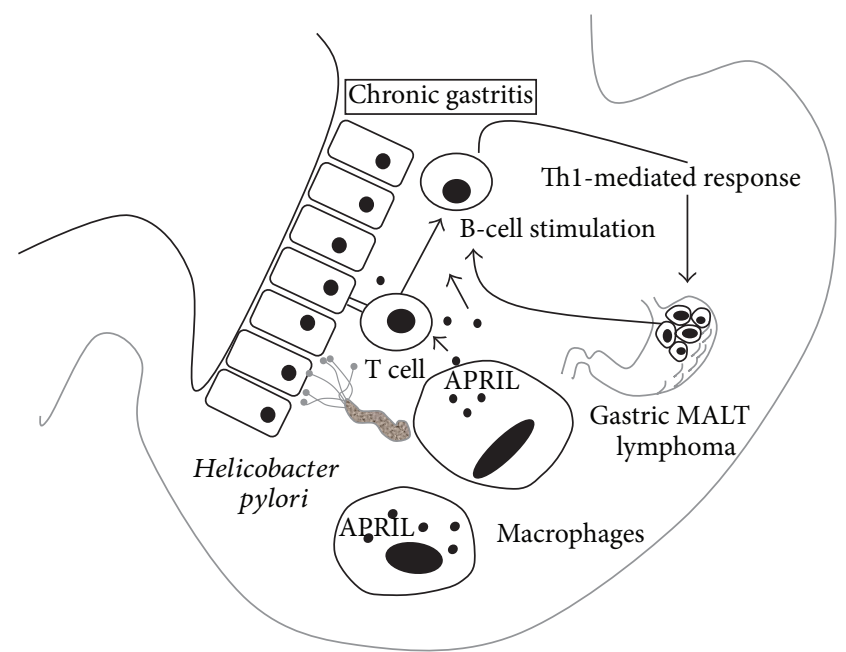

FIGURE 1: Helicobacter pylori-caused gastritis is crucial in an evolution of gastric MALT lymphoma localized in the stomach. In the gastric mucosal cells, there are elevated levels of some cytokines, including proliferation-inducing ligand (APRIL), the protein with a crucial role in B-cell maturation and survival. APRIL induces also B-cells transformation and the lymphoma progression. Gastritis attracted macrophages, which, under a Helicobacter pylori infection, release large amounts of APRIL.

lymphoid infiltrate similar to normal MALT tissue with huge amount of reactive clonal B lymphocytes. This situation is observed in salivary gland in patients with diagnosis of Sjögren syndrome and in the thyroid gland in Hashimoto disease. Sjögren syndrome is associated with 44 times increased risk of lymphoma [11], whereas Hashimoto's thyroiditis causes 70 times increased risk of thyroid lymphoma [12].

3.3. Genetic Abnormalities. Gastric MALT lymphoma is connected with many genetic abnormalities and transformations. Some of them are proven to be strongly associated with the disease, but some are still not confirmed. It is believed, that on the background of chronic inflammation not only reactive B-cells are stimulated but also activated neutrophils which can lead to production of oxygen species. As a result, this genotoxins provoke DNA damages, which are responsible for mutations and transformations of genetic material.

The best known abnormality is $\mathrm{t}(11 ; 18)(\mathrm{q} 21 ; \mathrm{q} 21)$, which was first described in 1989 [13]. It originates from a fusion of two proteins: apoptosis inhibitor 2 (API2) and paracaspase MALT lymphoma-translocation gene 1 (MALT1). It is extremely important that this translocation is present only in MALT lymphomas. What is more important is that while $\mathrm{t}(11 ; 18)(\mathrm{q} 21 ; \mathrm{q} 21)$ is detected, no other chromosome abnormality can be found [14]. Unfortunately, positive cases do not response to Helicobacter pylori eradication, but, in contrast, they do not transform to more aggressive diffusive large Bcell lymphoma [15]. It is known that complete remission can be seen in at least $20 \%$ of patients with $t(11 ; 18)(q 21 ; q 21)$. The incidence of positivity for this translocation MALT lymphoma is at approximately $20 \%$ in Europe $[16,17]$ but 
is not as common in the United States where only 5\% are positive [18].

Another translocation is detected in only $5 \%$ of gastric MALT lymphomas. Patients with $\mathrm{t}(1 ; 14)(\mathrm{p} 22 ; \mathrm{q} 32)$ or its variant $t(1 ; 2)(\mathrm{p} 22 ; \mathrm{p} 12)$ often have other genomic mutations. Moreover, it is usually connected with an advanced stage of disease and poor outcomes. BCL-10 gene is relocated from chromosome 1 to 14 , which in consequence triggers overexpression of Bcl-10 protein also known as CIPER, CARMEN, or mE10. In healthy organisms, higher expression is observed in lymph nodes, spleen, and testis. So far, it is believed that $\mathrm{Bcl}-10$ protein expression is responsible for proliferative effects $[19,20]$.

The $\mathrm{t}(14 ; 18)(\mathrm{q} 32 ; \mathrm{q} 21)(I G H-B C L-2)$ is commonly present in follicular lymphoma, in about $20 \%$ of diffuse large B-cell lymphoma and sometimes in chronic lymphocytic leukemia. Although this aberration is extremely rare in other types of lymphomas, it can be found in some cases of gastric MALT lymphoma. It was discovered that this aberration occurs more often in HCV-infected patients [21]. Bcl-2 is an antiapoptotic protein, which helps in survival and expansion of clonal B cells. So far, the role of $t(14 ; 18)$ in gastric MALT lymphoma is not fully understood. Overexpression of Bcl-2 is found not only in translocation positive patients but also in the negative ones. It is believed that similar to other types of lymphomas, $t(14 ; 18)(I G H-B C L-2)$ must coexist with other genetic abnormalities in order to develop neoplasm.

$\mathrm{t}(3 ; 14)(\mathrm{p} 14 ; \mathrm{q} 32)(I G H-F O X P 1)$ is a newly described abnormality present in patients with MALT lymphoma. This aberration causes overexpression of forkhead box (FOX)P1 mRNA and protein [22]. Accurate mechanism of how transcription factor FOXP1 leads to lymphogenesis is not fully discovered. The first study showed that positivity for this translocation is approximately $10 \%$ of all MALT lymphoma patients [22]. This abnormality is commonly found with other genetic aberrations. The most recent studies described the presence of $\mathrm{t}(3 ; 14)$ (p14; 32 ) in diffuse large B-cell lymphoma, outside the lymph nodes especially $[23,24]$. Only one study, so far, confirmed the existence of this translocation in gastric MALT lymphoma [25] which involved bad clinical outcomes.

In pathogenesis of MALT lymphoma, the above described translocation promotes oncogenesis by similar well-known mechanism. The majority of them involve the same pathway, which leads to antigen receptor-mediated activation of $\mathrm{NF} \kappa \mathrm{B}$. This is a crucial transcript factor which plays a key role in MALT lymphogenesis [26, 27]. It regulates processes connected with B-cell development, growth, and survival by production of cytokines and growth factors, for example, TNF- $\alpha$ family (BAFF). Latest studies have shown that B-cell activation in MALT lymphoma can be strictly connected with TNF family. It can be also responsible for activation of cell apoptosis $[28,29]$. It is observed that in patients with higher BAFF levels in serum, the prognosis and survival are much worse [30].

Based on recent knowledge about genetic abnormalities in gastric MALT lymphoma, there is a model of multistep pathogenesis. On the background of chronic inflammation and antigenic stimulation occurs genetic instability. As a result, many possible translocation and unbalanced aberrations are observed.

\section{Symptoms and Diagnosis}

The symptoms presented by patients with gastric MALT lymphoma are extremely unspecific. This causes difficulties with making final diagnosis and finding disease at an early stage. The signs of the disease are usually connected with involved location. Gastric MALT lymphoma can be longtime asymptomatic or associated with dyspepsia, abdominal pain, vomiting, diarrhea, obstruction, and nausea. Sometimes bleeding from gastrointestinal tract or even perforation may occur while extensive lesions are present. As a result, symptoms of anemia like paleness, weakness, or easy fatigue can be observed. B symptoms (weight loss, unexplained fever, and night sweats) in gastric MALT lymphoma are very rare, but the most common of the above is weight loss. A prompt diagnosis is crucial, but, unfortunately, it is usually made by incidence. Patients with early stage of disease have usually low tumor growth and minimal possibility to spread. The clinical course is indolent and there is a good response to the treatment. In contrast, patients with advanced stage of disease can undergo transformation to more aggressive lymphoma and may become resistant to treatment.

Not only symptoms but also endoscopic picture can be inconclusive. Difficulties often arise to differentiate between chronic gastritis or ulcer from an early-stage lymphoma. In order to confirm the diagnosis, a histopathologic evaluation of the gastric biopsies is indispensable. Routine histology and immunohistochemistry are required to correctly distinguish the disease. There always must be made PCR or FISH analysis for $t(11 ; 18)$, which is important to separate groups that will not respond to standard treatment. Characteristic for gastric MALT lymphoma are lymphoepithelial lesions (LEL) with the presence of mainly two types of cells: neoplastic centrocyte-like or small lymphoid. Occasionally, there can be seen atypical plasmacytic tumor cells. There is no specific immunohistochemical profile typical for gastric MALT lymphoma diagnosis. In $50 \%$ of patients, there is coexpression of CD43/BCL2. Neoplastic cells are positive for CD-20 and negative for CD-10, CD-23, and cyclin D1.

Moreover, Helicobacter pylori infection must be investigated. If it is negative in histochemistry, rapid urea breath test or fecal antigen test have to be made. Another analysis to prove absence of Helicobacter pylori infection is serological test for CagA antibodies and Helicobacter pylori-IgG antibodies [31]. Sometimes, there is possibility to detect other Helicobacter species, for example, heilmannii or felis [32].

\section{Staging and Risk Factors}

Before taking any decision on how aggressive the treatment should be, it is extremely important to perform a complete staging of the disease. What is more important is that risk factors and individual parameters, which can affect later therapy, are crucial. Medical history must include information about the age, time of the first symptoms, the family 
history, and medical condition. The most important factor that we rely on during choosing method of treatment is clinical stage of the patient. During physical examination, it is important to remember about Waldeyer's ring, which is mandatory in every gastric lymphoma patient. Staging in gastric MALT lymphoma is similar to that in other types of lymphomas. According to recent European Society for Medical Oncology (ESMO) recommendations [33], it should include morphology with basic biochemical studies. If the blood cell count is lower, it can be caused by infiltration of bone marrow. Biochemical tests can detect liver or kidney problems, which can be important before the beginning of a chemotherapy. It can also detect mineral abnormalities which should be corrected before treatment. Lactate dehydrogenase (LDH) and $\beta 2$-mikroglobulin are prognostic factors and will be abnormally high in patients with fast-growing tumor. Coagulogram is another important test which shows us if the blood is clotting properly. Every newly diagnosed patient should be examined in case of certain viral infections that can affect treatment, such as hepatitis B and C or human immunodeficiency virus (HIV).

In every case, computed tomography (CT) scans of neck, chest, abdomen, and pelvis, which are crucial to evaluate enlarged lymph nodes, should be performed. Core needle biopsy of bone marrow is made to diagnose possible infiltration of neoplastic cells. It was confirmed that $15 \%$ of gastric MALT lymphoma patients have lymphoma cells in bone marrow. Positron emission tomography (PET) has still not confirmed clinical necessity, but it can be extremely helpful in controversial cases. Moreover, during staging procedures of gastric MALT lymphoma, gastroduodenal endoscopy must be made. Biopsies are taken from different sites of gastrointestinal tract (e.g., stomach, duodenum, and gastroesophageal junction) and every location that looks suspicious.

There is no special staging scale for gastric MALT lymphomas. Most often, Ann Arbour staging is employed, which describe the extend of all types of non-Hodgkin lymphoma in adults. This classification was modified by Musshoff et al. [34]. Thus, staging of gastric lymphoma based upon the Ann Arbor system includes stage I E, which is disease limited to the stomach without nodal spread. Stage II $E_{1}$ is tumor in the stomach with spread to adjacent contiguous lymph nodes. Stage II $E_{2}$ is tumor in the stomach with spread to lymph nodes that are noncontiguous with the primary tumor. Moreover, if the spleen is affected, we add S. If the person has any of the B symptoms, we add letter B, and if is asymptomatic, we assign A (Table 1).

Prognostic factors in gastric MALT lymphoma are similar to the value for non-Hodgkin B-cells lymphoma. Factors that determine poor outcome are age, high level of $\mathrm{LDH}$ in serum, higher ECOG performance status, stages III and IV in Ann-Arbour scale, white blood count, and more than one extranodal site. It was observed that patients with nodal invasion has difficulty with complete remission after eradication treatment.

Some genetic abnormalities are thought to be bad prognostic factors. For instance patients, with $\mathrm{t}(11 ; 18)(\mathrm{q} 21 ; \mathrm{q} 21)$ especially, are resistant to the first line therapy, and remission
TABle 1: Ann Arbour clinical staging for gastric lymphoma.

\begin{tabular}{|c|c|}
\hline Stage & Localization \\
\hline I E & Confined within the gastric wall \\
\hline II $E_{1}$ & Involvement of stomach and contiguous lymph nodes \\
\hline $\mathrm{II} \mathrm{E}_{2}$ & $\begin{array}{l}\text { Involvement of stomach and noncontiguous } \\
\text { subdiaphragmatic lymph nodes }\end{array}$ \\
\hline III & Lymph nodes on both sides of the diaphragm \\
\hline IV & Visceral metastasis or second extranodal site \\
\hline
\end{tabular}

Subscripts that can be added to staging:

E: extranodal, when lymphoid tissue outside lymph nodes is involved.

$\mathrm{X}$ : is added when the largest diameter is above $10 \mathrm{~cm}$ (called bulky disease). $\mathrm{S}$ : is added when the spleen is involved.

$\mathrm{A}$ or $\mathrm{B}$ : B is added when one of B symptoms is present, and A is for asymptomatic patients.

rate was lower than that in patients of API2-MALT1 negative (78\% versus $22.2 \% ; P=0.0001$ ) [35]. That is why followup is so important in this group. Only one study so far proved that the presence of $\mathrm{t}(3 ; 14)$ (p14; $\mathrm{q} 32)$ is connected with poor clinical outcomes of patients with gastric MALT lymphoma [25].

\section{Treatment}

While Helicobacter pylori plays a main role in the pathogenesis of MALT lymphoma, it is also crucial in approach to the treatment. According to current international guidelines, first line treatment for localized Helicobacter pylori-positive patients should be dual eradication therapy [36-38]. The treatment may be used with every highly effective antibiotics against Helicobacter pylori, taking into consideration the locally expected antibiotic resistance. If there is no response to the therapy above, second line triple or quadruple therapy is used. It was reported that after two lines of treatment, $99.8 \%$ of patients were cured from gastritis [39]. In a large study of 1408 patients, remission after eradication treatment in early stage was observed in $77.5 \%$.

Unfortunately, in $5 \%-10 \%$ of gastric MALT lymphoma patients, we cannot confirm Helicobacter pylori infection. Moreover, more than $30 \%$ patients are resistant to first line treatment, and $30 \%$ of them have $\mathrm{t}(11 ; 18)(\mathrm{q} 21 ; \mathrm{q} 21)$. Treatment for this patients should be chosen individually depending on the clinical stage of disease. For those who have stable disease without any symptoms, the best approach is "watch and wait." This approach will be valid for older patients with comorbidities. Potential risk factors like molecular markers should be taken into consideration as well. Aggressive therapy should be considered in symptomatic or progressive disease. Radiotherapy, chemotherapy, and/or surgery can be considered after unsuccessful eradication treatment. Further recommended therapy in this group has not been established so far.

Surgery is considered to be a standard therapy in therapy of patients with gastric MALT lymphomas, but, recently, the value of this therapy has been not confirmed. Even if the lymphoma is localized at early stage, the gastrectomy should be rather extensive due to the nature of the disease. Sometimes 
TABLE 2: Chemo/immunotherapy lymphoma as a second line treatment in gastric MALT, phase II trials.

\begin{tabular}{|c|c|c|c|c|c|}
\hline Authors & Treatment & $n$ & CR & $\mathrm{PR}$ & SD \\
\hline Nakamura et al. 2005, [45] & Cyclophosphamide & 12 & $83 \%$ & & $17 \%$ \\
\hline Raderer et al. 2005, [49] & Oxaliplatin & 4 & $56 \%$ & $38 \%$ & $6 \%$ \\
\hline Jäger et al. 2006, [50] & Cladribine & 19 & $100 \%$ & & \\
\hline Martinelli et al. 2005, [51] & Rituximab & 27 & $46 \%$ & $31 \%$ & \\
\hline Conconi et al. 2011, [52] & Bortezomib & 13 & $46 \%$ & $15 \%$ & $31 \%$ \\
\hline Zinzani et al. 2004, [46] & Fludarabine and mitoxantrone & 20 & $100 \%$ & & \\
\hline Raderer et al. 2006, [53] & $\begin{array}{l}\text { R-CHOP (15 patients) } \\
\text { R-CNOP (11 patients) }\end{array}$ & 26 & $77 \%$ & $23 \%$ & \\
\hline Troch et al. 2013, [54] & Rituximab and cladribine & 40 & $58 \%$ & $23 \%$ & $13 \%$ \\
\hline Kiesewetter et al. 2012, [55] & Lenalidomide & 18 & $33 \%$ & $27.8 \%$ & $16.7 \%$ \\
\hline
\end{tabular}

$n$ : number of patients, CR: complete response, PR: partial response, SD: stable disease.

R-CHOP: rituximab plus cyclophosphamide, doxorubicin, vincristine, and prednisone.

R-CNOP: rituximab plus cyclophosphamide, mitoxantrone, vincristine, and prednisone.

further treatment is still required. Moreover, it is a major surgery and can be associated with serious complications and worsen a quality of life. German Multicenter Study Group (GMSG) presented no difference between survival in patients treated with gastrectomy compared to eradication (overall survival rate $82 \%$ to $84 \%$ ) [40]. What is more important is that there were observed $50 \%$ long-term complications were observed after surgery [41].

In few studies, there was confirmed an excellent disease control by using radiotherapy. The use of a modest dose of involved fields was performed on resistant-to-eradication therapy patients with early-stage disease. The dose was 2535 Gy to the stomach and perigastric nodes for the period of 4 weeks $[42,43]$. Compared to surgery, no serious long-term complications and toxicity were observed. Only nausea and anorexia were present during the time of radiotherapy.

For a long time it was believed that gastric MALT lymphoma is just a localized disease and that surgery and radiotherapy are the best treatment strategy. Now, when it is well known that it is disseminated disorder chemotherapy, it became more important. Still, there are no standard recommendations for relapse or progressive patients after therapy and for those with late stage of the disease from the beginning. It was observed that chemotherapy alone is more effective than surgery apart from some cases with gastric obstruction [44]. Many chemotherapeutics are tested. The most commonly used are alkylating agents, nucleoside analogs in combination with corticosteroids. Complete remission (CR) after oral monochemotherapy with cyclophosphamide was $83 \%$ in a study by Nakamura and coworkers [45]. Unfortunately, patients with positive translocation $t(11 ; 18)$ are resistant to second line therapy with oral monochemotherapy with alkylating agents. Nucleoside analogs are confirmed to be effective in treatment of different kinds of indolent lymphomas. A polychemotherapy with fludarabine and mitoxantrone (FM) has a very good effect on patients with gastric MALT lymphoma in both first and second line treatment. All groups that consisted of 20 people achieved complete remission [46]. Also the role of cladribine or 2-chlorodeoxyadenosine (2$\mathrm{CdA}$ ) was investigated. The complete remission after 4 cycles achieved $84 \%$ of investigated and all of them reacted to the treatment [47]. It is important that patients with translocation $\mathrm{t}(11 ; 18)$ respond to therapy as well [48]. After 2-CdA, there were observed complications such as toxicities of 3 and 4 grade of WHO, mainly leukopenia, infections, and secondary neoplastic disease. There are highly effective drugs which should be individually considered in each patient.

Nowadays, immunotherapy became an extremely important part of treatment of non-Hodgkin lymphomas. The most commonly used is rituximab. It is a chimeric mouse/human monoclonal antibody specified to CD20 antigen expressed on the surface of B lymphocytes. Firstly, its effectiveness was shown in follicular lymphoma [56]. Now it is widely used alone or in combination with chemotherapeutic drugs in many types of B-cell non-Hodgkin lymphomas. Rituximab binds to CD20 antigen and activates the lysis of B cells by mediating cytotoxicity of complement dependent (CDC) and cell-mediated cytotoxicity antibody dependent (ADCC). It is also believed to induce cell death by apoptotic mechanism. The role of this drug is still not clear in gastric MALT lymphoma. In 2003, there was a first-phase study by Conconi et al. [57] with rituximab in monotherapy in patients at any stage. The CR was observed in $29 \%$ and overall response rate (ORR) was $64 \%$. The toxicity of this treatment was moderate or even mild, but the relapse rate was $36 \%$. An important fact is that patients with translocation $t(11 ; 18)$ are responsive to rituximab treatment $[58,59]$. What is more important is that in a study by the International Extranodal Lymphoma Study Group (IELSG), it was confirmed that chlorambucil in combination with rituximab was more effective than chlorambucil alone [60]. Also in phase II clinical trial by Troch et al. CR by rituximab with cladribine was achieved by $58 \%$ of patients [54]. The conclusion is that rituximab may a benefit in individual patients, but for the majority it is not sufficient when used alone. It is more effective in combination with standard chemotherapeutics.

The efficacy of the combination of rituximab with chlorambucil was evaluated in a randomized study (comparator was chlorambucil alone) by the International Extranodal Lymphoma Study Group (IELSG) in gastric MALT 
lymphomas that had failed antibiotics and in nongastric MALT lymphomas. The preliminary report [40] showed that the 5-year event-free survival was significantly better for patients treated with chlorambucil plus rituximab. There were also studies by Raderer et al. with cycles generally used in more aggressive lymphomas. Twenty-six patients were administrated rituximab plus cyclophosphamide, doxorubicin or mitoxantrone, vincristine, and prednisone. Complete remission was observed in $77 \%$ and partial remission was achieved in $27 \%$ [53]. Lately, bortezomib, the first therapeutic proteasome inhibitor, was examined by Kiesewetter et al. in 2012 with CR in 33\% and PR in 27.8\% [55]. The results on phase II studies with chemotherapy and immunotherapy are shown in Table 2.

Still the place of autologous hematopoietic stem cell transplantation is unknown. So far, it is not a standard for treatment of indolent lymphomas. Outcomes in gastric MALT lymphoma patients with progressive, disseminated disease are very comparable with outcomes in follicular lymphoma.

\section{Followup}

Although gastric MALT lymphoma has a very favorable outcome, it is still important to have a proper followup. It is possible that the disease will return even after 5 years of complete remission. The relapse can be due to reinfection of Helicobcater pylori. In a study by Zullo et al., reinfection was observed in $2.7 \%$ [61]. The followup is obligatory in patients with gastric MALT lymphoma to identify early phase of the recurrence of the disease. To confirm a complete remission, there should be done both endoscopic and histological examination. Although, there are no specified recommendations for a followup, the biopsy of gastric sites should be made every 6 months in first two years, and later once a year for the next five years. Systemic followup consist of blood tests and minimal adequate radiological and ultrasound and should be made at least once a year in the first 5 years. The most common are chest X-ray and abdomen ultrasound. The transformation in more aggressive lymphoma is low at the level of $0.05 \%$ [35], but there is a higher risk of occurrence of secondary neoplasm [62] and gastric cancer [63]. These studies confirm that patients with gastric MALT lymphoma need a long-term followup not only to detect early recurrence but also to find secondary disease.

\section{Conclusions}

Recently, enormous progress has been made in better understanding of pathogenesis of gastric MALT lymphoma. Many important chromosome aberrations, such as $\mathrm{t}(11 ; 18)$, have been detected. It has a great influence on the development of new and more effective treatment strategy. There still remain cellular and molecular routes that need to be explored and clarified. Still, not enough clinical trials are performed due to rare expression and high effectiveness of first line treatment of gastric MALT lymphoma. What is more important is that early diagnosis of gastric MALT lymphoma is extremely important. While the symptoms are unspecific or not, always during the endoscopic exam the complete histological biopsies must be taken to make diagnosis correctly. The less advanced the stage of the disease, the bigger the chances to achieve complete remission.

\section{Acknowledgments}

This work was supported under Grant no. 503/8-093-01/50301 from the Medical University of Lodz, Poland.

\section{References}

[1] P. Isaacson and M. Du, "MALT lymphoma: from morphology to molecules," Nature Reviews, vol. 52, no. 4, pp. 644-653, 2004.

[2] S. H. Swerdlow, WHO Classification of Tumours of Haematopoietic and Lymphoid Tissues, IARC, Lyon, France, 4th edition, 2007.

[3] D. M. Weber, M. A. Dimopoulos, D. P. Anandu, W. C. Pugh, and G. Steinbach, "Regression of gastric lymphoma of mucosaassociated lymphoid tissue with antibiotic therapy for Helicobacter pylori," Gastroenterology, vol. 107, no. 6, pp. 1835-1838, 1994.

[4] B. J. Marshall and J. R. Warren, "Unidentified curved bacilli in the stomach of patients with gastritis and peptic ulceration," The Lancet, vol. 1, no. 8390, pp. 1311-1314, 1984.

[5] N. Uemura, S. Okamoto, S. Yamamoto et al., "Helicobacter pylori infection and the development of gastric cancer," The New England Journal of Medicine, vol. 345, no. 11, pp. 784-789, 2001.

[6] A. Morgner, E. Bayerdörffer, A. Neubauer, and M. Stolte, "Malignant tumors of the stomach: gastric mucosa-associated lymphoid tissue lymphoma and Helicobacter pylori," Gastroenterology Clinics of North America, vol. 29, no. 3, pp. 593-607, 2000.

[7] P. M. Banks, "Gastrointestinal lymphoproliferative disorders," Histopathology, vol. 50, no. 1, pp. 42-54, 2007.

[8] J. L. O'Rourke, "Gene expression profiling in Helicobacterinduced MALT lymphoma with reference to antigen drive and protective immunization," Journal of Gastroenterology and Hepatology, vol. 23, no. 2, pp. S151-S156, 2008.

[9] F. Munari, S. Lonardi, M. A. Cassatella et al., “Tumor-associated macrophages as major source of APRIL in gastric MALT lymphoma," Blood, vol. 117, no. 24, pp. 6612-6616, 2011.

[10] F. Suarez, O. Lortholary, O. Hermine, and M. Lecuit, "Infectionassociated lymphomas derived from marginal zone B cells: a model of antigen-driven lymphoproliferation," Blood, vol. 107, no. 8, pp. 3034-3044, 2006.

[11] B. Royer, D. Cazals-Hatem, J. Sibilia et al., "Lymphomas in patients with Sjogren's syndrome are marginal zone B-cell neoplasms, arise in diverse extranodal and nodal sites, and are not associated with viruses," Blood, vol. 90, no. 2, pp. 766-775, 1997.

[12] G. A. Derringer, L. D. R. Thompson, R. A. Frommelt, K. E. Bijwaard, C. S. Heffess, and S. L. Abbondanzo, "Malignant lymphoma of the thyroid gland: a clinicopathologic study of 108 cases," The American Journal of Surgical Pathology, vol. 24, no. 5, pp. 623-639, 2000.

[13] E. G. Levine, D. C. Arthur, J. Machnicki et al., "Four new recurring translocations in non-Hodgkin lymphoma," Blood, vol. 74, no. 5, pp. 1796-1800, 1989. 
[14] P. Starostik, J. Patzner, A. Greiner et al., "Gastric marginal zone B-cell lymphomas of MALT type develop along 2 distinct pathogenetic pathways," Blood, vol. 99, no. 1, pp. 3-9, 2002.

[15] H. Liu, A. Ruskon-Fourmestraux, A. Lavergne-Slove et al., "Resistance of $\mathrm{t}(11 ; 18)$ positive gastric mucosa-associated lymphoid tissue lymphoma to Helicobacter pylori eradication therapy," The Lancet, vol. 357, no. 9249, pp. 39-40, 2001.

[16] B. Streubel, I. Simonitsch-Klupp, L. Müllauer et al., "Variable frequencies of MALT lymphoma-associated genetic aberrations in MALT lymphomas of different sites," Leukemia, vol. 18, no. 10, pp. 1722-1726, 2004.

[17] H. Ye, L. Gong, H. Liu et al., "MALT lymphoma with $\mathrm{t}(14 ; 18)(\mathrm{q} 32 ; \mathrm{q} 21) / \mathrm{IGH}-\mathrm{MALT} 1$ is characterized by strong cytoplasmic MALT1 and BCL10 expression," The Journal of Pathology, vol. 205, no. 3, pp. 293-301, 2005.

[18] E. D. Remstein, A. Dogan, R. R. Einerson et al., "The incidence and anatomic site specificity of chromosomal translocations in primary extranodal marginal zone B-cell lymphoma of mucosaassociated lymphoid tissue (MALT lymphoma) in North America," The American Journal of Surgical Pathology, vol. 30, no. 12, pp. 1546-1553, 2006.

[19] J. Ruland, G. S. Duncan, A. Elia et al., "Bcl10 is a positive regulator of antigen receptor-induced activation of NF- $\kappa \mathrm{B}$ and neural tube closure," Cell, vol. 104, no. 1, pp. 33-42, 2001.

[20] L. Xue, S. W. Morris, C. Orihuela et al., "Defective developmental and function of Bcl10-deficient follicular, marginal zone and B1 B cells," Nature Immunology, vol. 4, no. 9, pp. 857-865, 2003.

[21] M. Libra, V. De Re, A. Gloghini et al., "Detection of bcl-2 rearrangement in mucosa-associated lymphoid tissue lymphomas from patients with hepatitis C virus infection," Haematologica, vol. 89, no. 7, pp. 873-874, 2004.

[22] B. Streubel, U. Vinatzer, A. Lamprecht, M. Raderer, and A. Chott, "T(3;14)(p14.1;q32) involving IGH and FOXP1 is a novel recurrent chromosomal aberration in MALT lymphoma," Leukemia, vol. 19, no. 4, pp. 652-658, 2005.

[23] E. D. Remstein, A. Dogan, R. R. Einerson et al., "The incidence and anatomic site specificity of chromosomal translocations in primary extranodal marginal zone B-cell lymphoma of mucosaassociated lymphoid tissue (MALT lymphoma) in North America," The American Journal of Surgical Pathology, vol. 30, no. 12, pp. 1546-1553, 2006.

[24] E. Haralambieva, P. Adam, R. Ventura et al., "Genetic rearrangement of FOXP1 is predominantly detected in a subset of diffuse large B-cell lymphomas with extranodal presentation," Leukemia, vol. 20, no. 7, pp. 1300-1303, 2006.

[25] X. Sagaert, P. De Paepe, L. Libbrecht et al., "Forkhead box protein $\mathrm{P} 1$ expression in mucosa-associated lymphoid tissue lymphomas predicts poor prognosis and transformation to diffuse large B-cell lymphoma," Journal of Clinical Oncology, vol. 24, no. 16, pp. 2490-2497, 2006.

[26] M. Thome, "CARMA1, BCL-10 and MALT1 in lymphocyte development and activation," Nature Reviews Immunology, vol. 4, no. 5, pp. 348-359, 2004.

[27] X. Lin and D. Wang, "The roles of CARMA1, Bcl10, and MALT1 in antigen receptor signaling," Seminars in Immunology, vol. 16, no. 6, pp. 429-435, 2004.

[28] Y. Y. Pei, S. H. Kuo, K. H. Yeh et al., "A pathway for tumor necrosis factor- $\alpha$-induced Bcl10 nuclear translocation: Bcl10 is up-regulated by NF- $\kappa \mathrm{B}$ and phosphorylated by Aktl and then complexes with $\mathrm{Bcl} 3$ to enter the nucleus," The Journal of Biological Chemistry, vol. 281, no. 1, pp. 167-175, 2006.
[29] M. Batten, C. Fletcher, L. G. Ng et al., "TNF deficiency fails to protect BAFF transgenic mice against autoimmunity and reveals a predisposition to B cell lymphoma," Journal of Immunology, vol. 172, no. 2, pp. 812-822, 2004.

[30] A. J. Novak, D. M. Grote, M. Stenson et al., "Expression of BLyS and its receptors in B-cell non-Hodgkin lymphoma: correlation with disease activity and patient outcome," Blood, vol. 104, no. 8, pp. 2247-2253, 2004.

[31] J. E. Everhart, D. Kruszon-Moran, and G. Perez-Perez, "Reliability of Helicobacter pylori and CagA serological assays," Clinical and Diagnostic Laboratory Immunology, vol. 9, no. 2, pp. 412416, 2002.

[32] J. G. Fox, "The non-H pylori helicobacters: their expanding role in gastrointestinal and systemic diseases," Gut, vol. 50, no. 2, pp. 273-283, 2002.

[33] E. Zucca and M. Dreyling, "Gastric marginal zone lymphoma of MALT type: ESMO clinical practice guidelines for diagnosis, treatment and follow-up," Annals of Oncology, vol. 21, supplement 5, pp. v175-v176, 2010.

[34] K. Musshoff and H. Schmidt Vollmer, "Prognosis of non Hodgkin's lymphomas with special emphasis on the staging classification," Zeitschrift fur Krebsforschung und Klinische Onkologie, vol. 83, no. 4, pp. 323-341, 1975.

[35] A. Zullo, C. Hassan, F. Cristofari et al., "Effects of Helicobacter pylori eradication on early stage gastric mucosa-associated lymphoid tissue lymphoma," Clinical Gastroenterology and Hepatology, vol. 8, no. 2, pp. 105-110, 2010.

[36] M. Caselli, A. Zullo, G. Maconi et al., "'Cervia II Working Group Report 2006': guidelines on diagnosis and treatment of Helicobacter pylori infection in Italy," Digestive and Liver Disease, vol. 39, no. 8, pp. 782-789, 2007.

[37] P. Malfertheiner, F. Megraud, C. O. 'Morain et al., "Current concepts in the management of Helicobacter pylori infection: the Maastricht III Consensus Report," Gut, vol. 56, no. 6, pp. 772 781, 2007.

[38] K. M. Fock, P. Katelaris, K. Sugano et al., "Second Asia-Pacific consensus guidelines for Helicobacter pylori infection," Journal of Gastroenterology and Hepatology, vol. 24, no. 10, pp. 1587$1600,2009$.

[39] A. Zullo, C. Hassan, A. Andriani et al., "Eradication therapy for Helicobacter pylori in patients with gastric MALT lymphoma: a pooled data analysis," The American Journal of Gastroenterology, vol. 104, no. 8, pp. 1932-1937, 2009.

[40] P. Koch, F. Del Valle, W. E. Berdel et al., "Primary gastrointestinal non-Hodgkin's lymphoma: II. Combined surgical and conservative or conservative management only in localized gastric lymphoma-results of the prospective German multicenter study GIT NHL 01/92," Journal of Clinical Oncology, vol. 19, no. 18, pp. 3874-3883, 2001.

[41] D. L. Bartlett, M. S. Karpeh Jr., D. A. Filippa, and M. F. Brennan, "Long-term follow-up after curative surgery for early gastric lymphoma," Annals of Surgery, vol. 223, no. 1, pp. 53-62, 1996.

[42] J. Yahalom, "MALT lymphomas: a radiation oncology viewpoint," Annals of Hematology, vol. 80, supplement 3, pp. B100B105, 2001.

[43] P. Koch, A. Probst, W. E. Berdel et al., "Treatment results in localized primary gastric lymphoma: data of patients registered within the German Multicenter study (GIT NHL 02/96)," Journal of Clinical Oncology, vol. 23, no. 28, pp. 7050-7059, 2005.

[44] S. S. Yoon, D. G. Coit, C. S. Portlock, and M. S. Karpeh, "The diminishing role of surgery in the treatment of gastric lymphoma," Annals of Surgery, vol. 240, no. 1, pp. 28-37, 2004. 
[45] S. Nakamura, T. Matsumoto, H. Suekane et al., "Long-term clinical outcome of Helicobacter pylori eradication for gastric mucosa-associated lymphoid tissue lymphoma with a reference to second-line treatment," Cancer, vol. 104, no. 3, pp. 532-540, 2005.

[46] P. L. Zinzani, V. Stefoni, G. Musuraca et al., "Fludarabinecontaining chemotherapy as frontline treatment of nongastrointestinal mucosa-associated lymphoid tissue lymphoma," Cancer, vol. 100, no. 10, pp. 2190-2194, 2004.

[47] G. Jäger, P. Neumeister, R. Brezinschek et al., “Treatment of extranodal marginal zone B-cell lymphoma of mucosaassociated lymphoid tissue type with cladribine: a Phase II study," Journal of Clinical Oncology, vol. 20, no. 18, pp. 38723877, 2002.

[48] B. Streubel, H. Ye, M. Q. Du, P. G. Isaacson, A. Chott, and M. Raderer, "Translocation $\mathrm{t}(11 ; 18)(\mathrm{q} 21 ; \mathrm{q} 21)$ is not predictive of response to chemotherapy with $2 \mathrm{CdA}$ in patients with gastric MALT lymphoma," Oncology, vol. 66, no. 6, pp. 476-480, 2004.

[49] M. Raderer, S. Wohrer, R. Bartsch et al., "Phase II Study of oxaliplatin for treatment of patients with mucosa-associated lymphoid tissue lymphoma," Journal of Clinical Oncology, vol. 23, no. 33, pp. 8442-8446, 2005.

[50] G. Jäger, P. Neumeister, F. Quehenberger, S. Wöhrer, W. Linkesch, and M. Raderer, "Prolonged clinical remission in patients with extranodal marginal zone B-cell lymphoma of the mucosa-associated lymphoid tissue type treated with cladribine: 6 year follow-up of a phase II trial," Annals of Oncology, vol. 17, no. 11, pp. 1722-1723, 2006.

[51] G. Martinelli, D. Laszlo, A. J. M. Ferreri et al., "Clinical activity of rituximab in gastric marginal zone non-Hodgkin's lymphoma resistant to or not eligible for anti-Helicobacter pylori therapy," Journal of Clinical Oncology, vol. 23, no. 9, pp. 1979-1983, 2005.

[52] A. Conconi, G. Martinelli, A. Lopez-Guillermo et al., "Clinical activity of bortezomib in relapsed/refractory MALT lymphomas: results of a phase II study of the International Extranodal Lymphoma Study Group (IELSG)," Annals of Oncology, vol. 22, no. 3, pp. 689-695, 2011.

[53] M. Raderer, S. Wöhrer, B. Streubel et al., "Activity of rituximab plus cyclophosphamide, doxorubicin/mitoxantrone, vincristine and prednisone in patients with relapsed MALT lymphoma," Oncology, vol. 70, no. 6, pp. 411-417, 2006.

[54] M. Troch, B. Kiesewetter, W. Willenbacher et al., "Rituximab plus subcutaneous cladribine in patients with extranodal marginal zone B-cell lymphomaof the mucosa associated lymphoid tissue-Lymphoma: a phase II study by the Arbeitsgemeinschaft Medikamentose Tumortherapie," Haematologica, vol. 98, no. 2, pp. 264-268, 2013.

[55] B. Kiesewetter, M. Troch, W. Dolak et al., "A phase II study of lenalidomide in patients with extranodal marginal zone B-cell lymphoma of the mucosa associated lymphoid tissue (MALTlymphoma)," Haematologica. In press.

[56] P. McLaughlin, A. J. Grillo-López, B. K. Link et al., "Rituximab chimeric anti-CD20 monoclonal antibody therapy for relapsed indolent lymphoma: half of patients respond to a four-dose treatment program," Journal of Clinical Oncology, vol. 16, no. 8, pp. 2825-2833, 1998.

[57] A. Conconi, G. Martinelli, C. Thiéblemont et al., "Clinical activity of rituximab in extranodal marginal zone B-cell lymphoma of MALT type," Blood, vol. 102, no. 8, pp. 2741-2745, 2003.

[58] N. Chaudhary, H. Ozer, D. Huard, S. Lightfoot, and S. Mesiya, "Successful treatment of Helicobacter pylori-negative gastric
MALT lymphoma with rituximab," Digestive Diseases and Sciences, vol. 51, no. 4, pp. 775-778, 2006.

[59] A. Salar, B. Bellosillo, S. Serrano, and C. Besses, "Persistent residual disease in $\mathrm{t}(11 ; 18)(\mathrm{q} 21 ; \mathrm{q} 21)$ positive gastric mucosaassociated lymphoid tissue lymphoma treated with chemotherapy or rituximab," Journal of Clinical Oncology, vol. 23, no. 29, pp. 7361-7362, 2005.

[60] E. Zucca, A. Conconi, G. Martinelli et al., "Chlorambucil plus rituximab produces better eventfree survival in comparison with chlorambucil alone in the treatment of MALT lymphoma: 5 -year analysis of the 2-arms part of the IELSG-19 randomized study," Blood, vol. 116, p. 432, 2010, (ASH Annual Meeting Abstracts).

[61] A. Zullo, C. Hassan, A. Andriani et al., "Eradication therapy for Helicobacter pylori in patients with gastric MALT lymphoma: a pooled data analysis," The American Journal of Gastroenterology, vol. 104, no. 8, pp. 1932-1937, 2009.

[62] A. Andriani, A. Miedico, L. Tedeschi et al., "Management and long-term follow-up of early stage $H$. pylori-associated gastric MALT-lymphoma in clinical practice: an Italian, Multicentre study," Digestive and Liver Disease, vol. 41, no. 7, pp. 467-473, 2009.

[63] L. G. Capelle, A. C. de Vries, C. W. N. Looman et al., "Gastric MALT lymphoma: epidemiology and high adenocarcinoma risk in a nation-wide study," European Journal of Cancer, vol. 44, no. 16, pp. 2470-2476, 2008. 


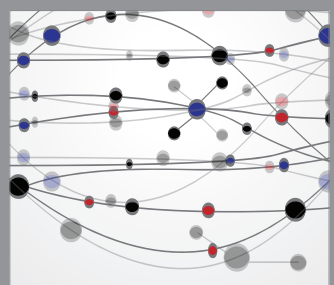

The Scientific World Journal
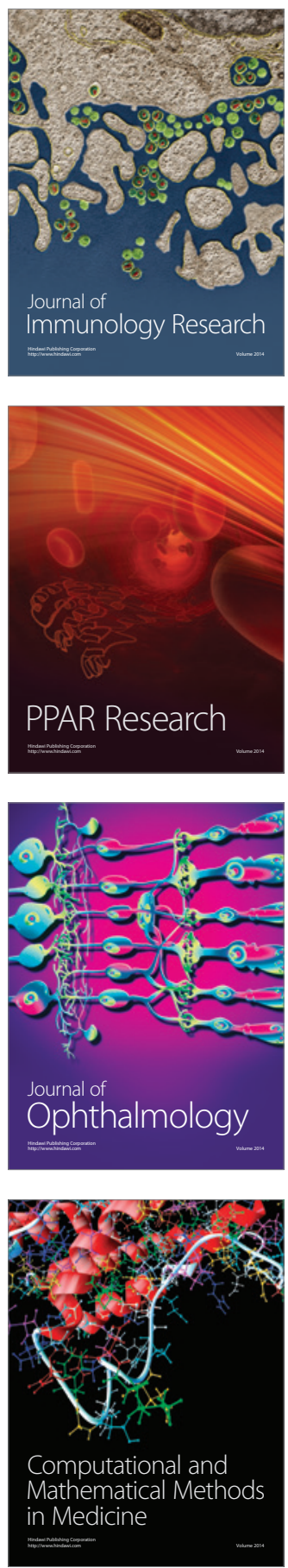

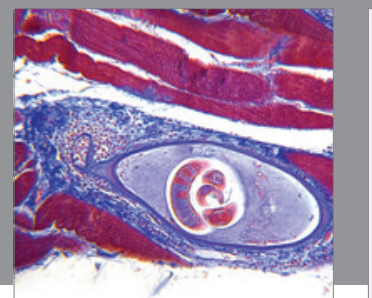

Gastroenterology

Research and Practice
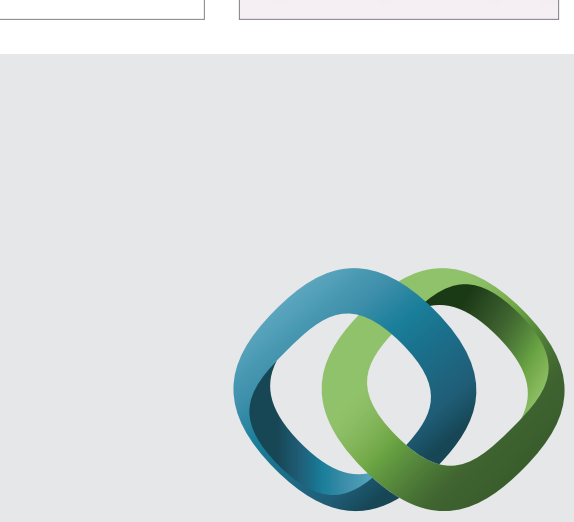

\section{Hindawi}

Submit your manuscripts at

http://www.hindawi.com
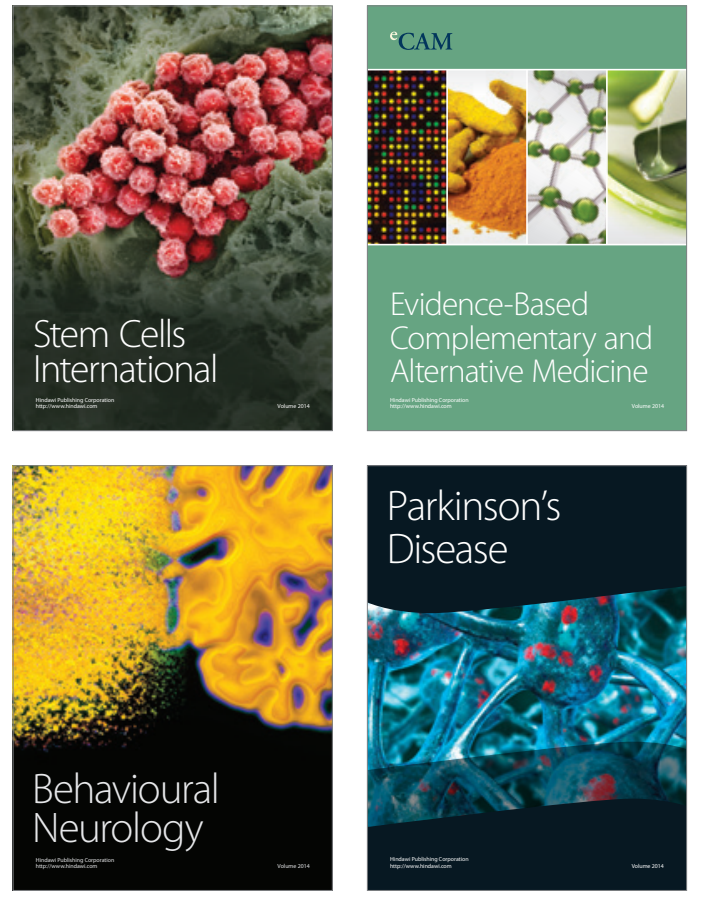
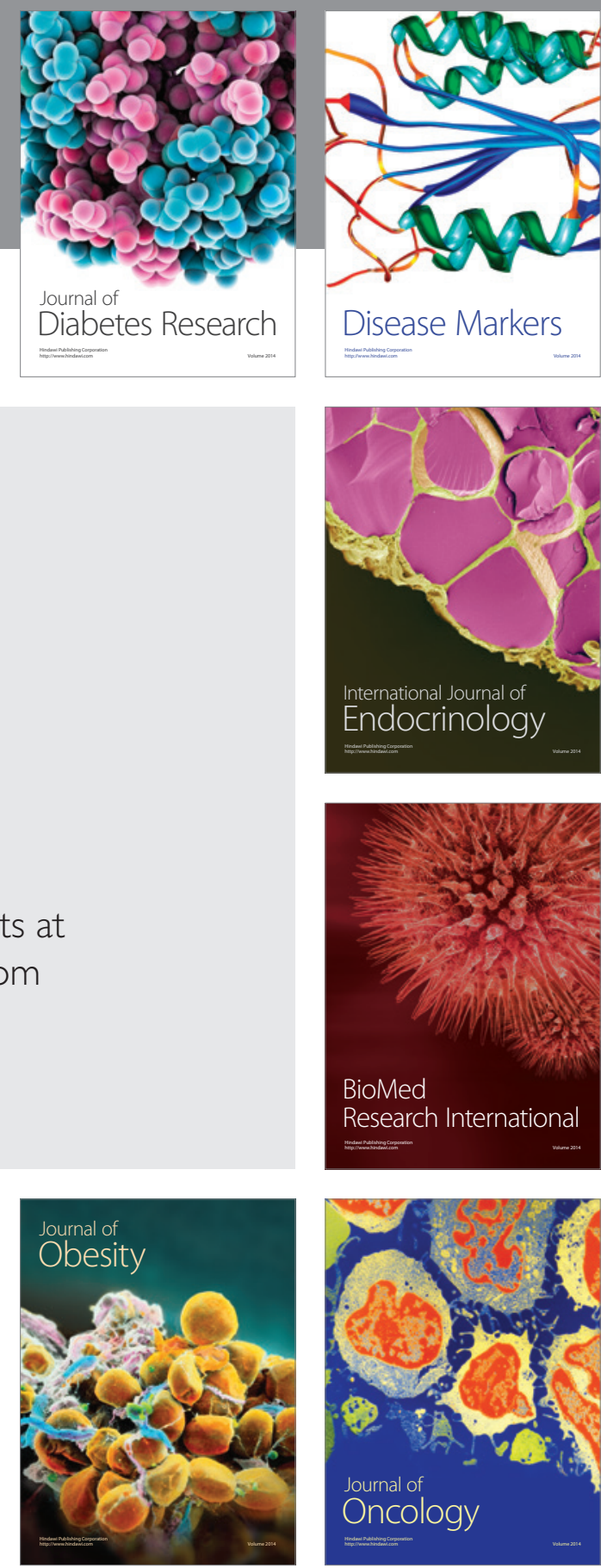

Disease Markers
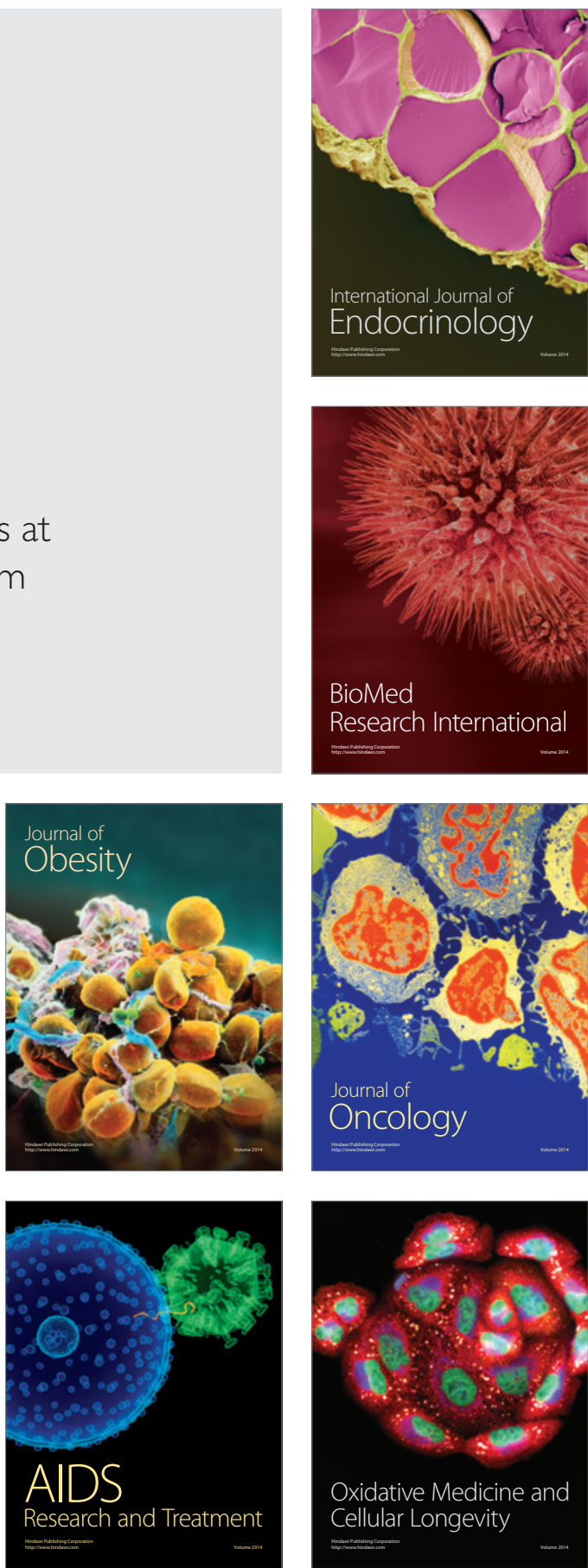